\title{
The Thermal Current in Lake Michigan ${ }^{1}$
}

\author{
Joseph Chi Kan Huang ${ }^{2}$ \\ Scripps Institution of Oceanography, La Jolla, Calif.
}

(Manuscript received 8 July 1970)

\begin{abstract}
A theoretical and observational study is made of the thermally induced circulation in Lake Michigan. The temperature and the velocity field are obtained by solving the coupled equations of motion and the energy equation using a regular perturbation together with the method of matched asymptotic expansion. Different horizontal and vertical eddy diffusion coefficients are used.

Two types of circulation patterns are found. The type A circulation is dominated by a cyclonic meridional flow with upwelling at the edges, while that of type B is anticyclonic with upwelling in the middle.

Comparisons between the theoretical results and the previously published and presently observed data show very good qualitative, and to some extent, quantitative agreement for the corresponding seasons. This leads one to postulate that the thermal body force does play an important role in the mean lake circulation.
\end{abstract}

\section{Introduction}

The Laurentian Great Lakes constitute the largest body of fresh water in the world and have long been considered as the inland "oceans" of the North American Continent. In spite of various differences between the properties of oceans and those of freshwater lakes, general physical phenomena in the two remain quite similar. As Rossby pointed out, the special characteristics of a fresh-water lake, such as negligible salinity and tides, and the more tractable boundary conditions, make the lake an ideal huge hydrodynamic laboratory. In recent years great emphasis has been given to the value of the lakes as testing basins for oceanographic studies and to understanding all aspects of limnological dynamics. Fig. 1 shows the Great Lakes and their mean currents during the warmer months (after Millar, 1952).

The climate in the Great Lakes region is typically humid continental with a severe winter and warm summer. The continental climate, modified by the land-sea breeze and the stabilizing effect of the lakes, gives this region more rapidly changing and complex weather patterns than those of the maritime region. The wind is variable both in magnitude and in direction. Although westerly winds prevail, winds from any direction are likely to be encountered, shifting in relation to the particular position with respect to the moving pressure centers (U. S. Weather Bureau, 1959).

The general annual thermal cycles of the Great Lakes are typical for a dimictic lake in the temperate zone as discussed by Hutchinson (1957). The lake is partially

\footnotetext{
1 Partly in the Special Rept. 43, Great Lakes Research Division, The University of Michigan, Ann Arbor.

${ }^{2}$ Research undertaken while author was at the University of Michigan.
}

ice-covered in winter, quasi-homogeneous from November to June, and strongly stratified during late summer and most of the autumn.

Due to the differences in specific heat and thermal conductivity between the earth soil and the lake water, a temperature gradient (either lakeward or shoreward) always exists along the perimeter of the lake during warming-up or cooling-off seasons. Fig. 2 shows the surface temperature pattern in July 1962 (McFadden and Ragotzkie, 1963). At different stages of seasonal progress in a year, the surface temperature profile on a traverse across the lake is bowl shaped with the two edges of the lake at highest or lowest temperatures.

It is well-documented, both theoretically [e.g., Eady (1949); Davies (1956, 1959); Kuo (1957); Robinson (1959); Brindley (1960); Barcilon (1964); Hunter (1967)] and experimentally [e.g., Fultz (1953); Hide (1953, 1958); Fowlis (1963); Fowlis and Hide (1965)] that for a small thermal Rossby number and a large Taylor number, flow in the lower symmetrical regime is expected to occur in a differentially heated fluid. The purpose of the present paper is to study the flow in Lake Michigan, considering the thermal gradient force as the prime source for the mean current structure in the lake, and to investigate the thermal circulation pattern of the lake that results.

\section{Formulation of the problem}

The length of Lake Michigan is much grea ter than the average width. The north end of the lake is connected through the broad and deep Strait of Mackinac to Lake Huron, which is at the same sea level as Lake Michigan. An east-west cross section of the lower central part of Lake Michigan is shown in Fig. 3.

To simulate Lake Michigan, a long symmetrical trough, trapezoidal in cross section, filled with fresh 


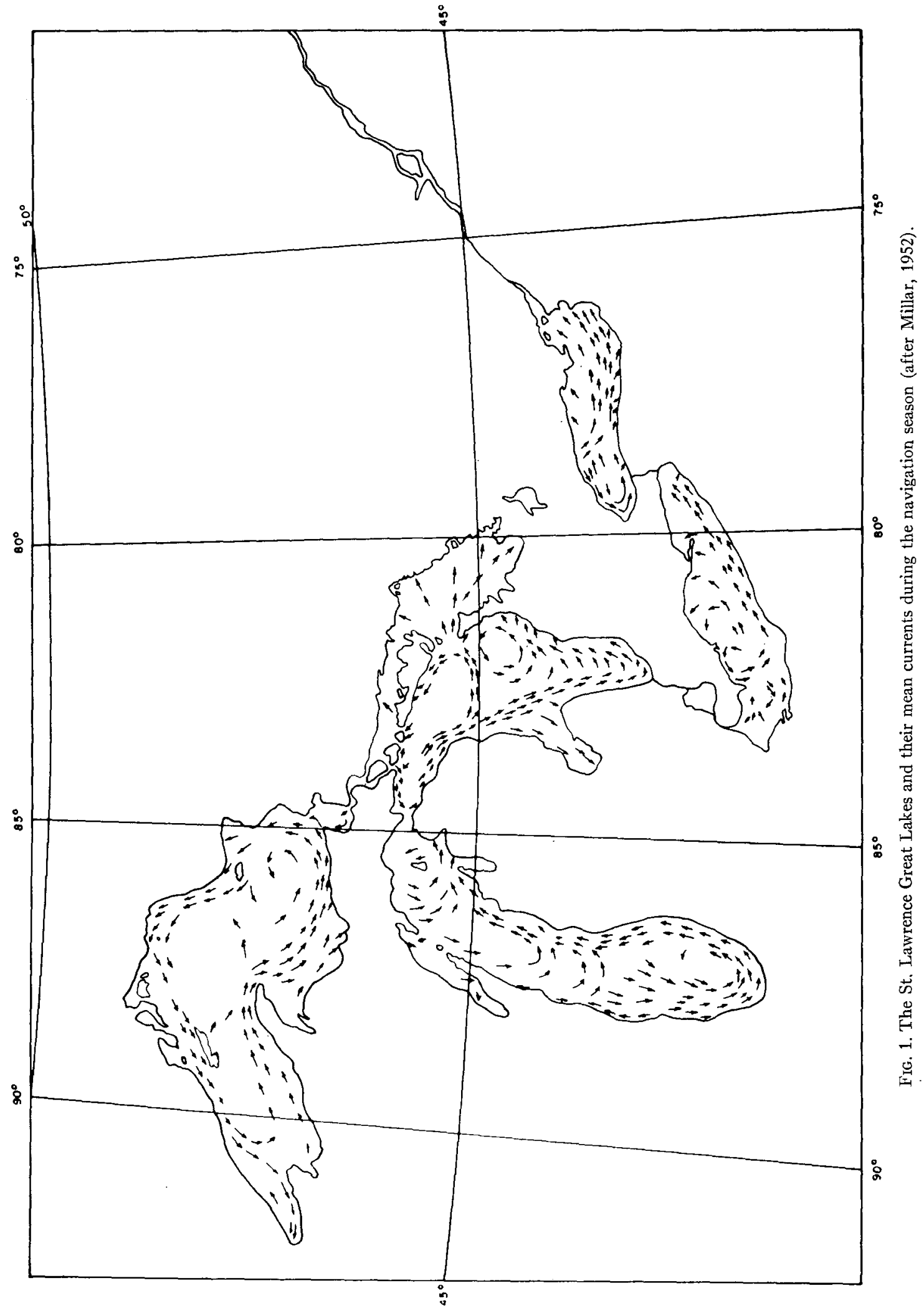




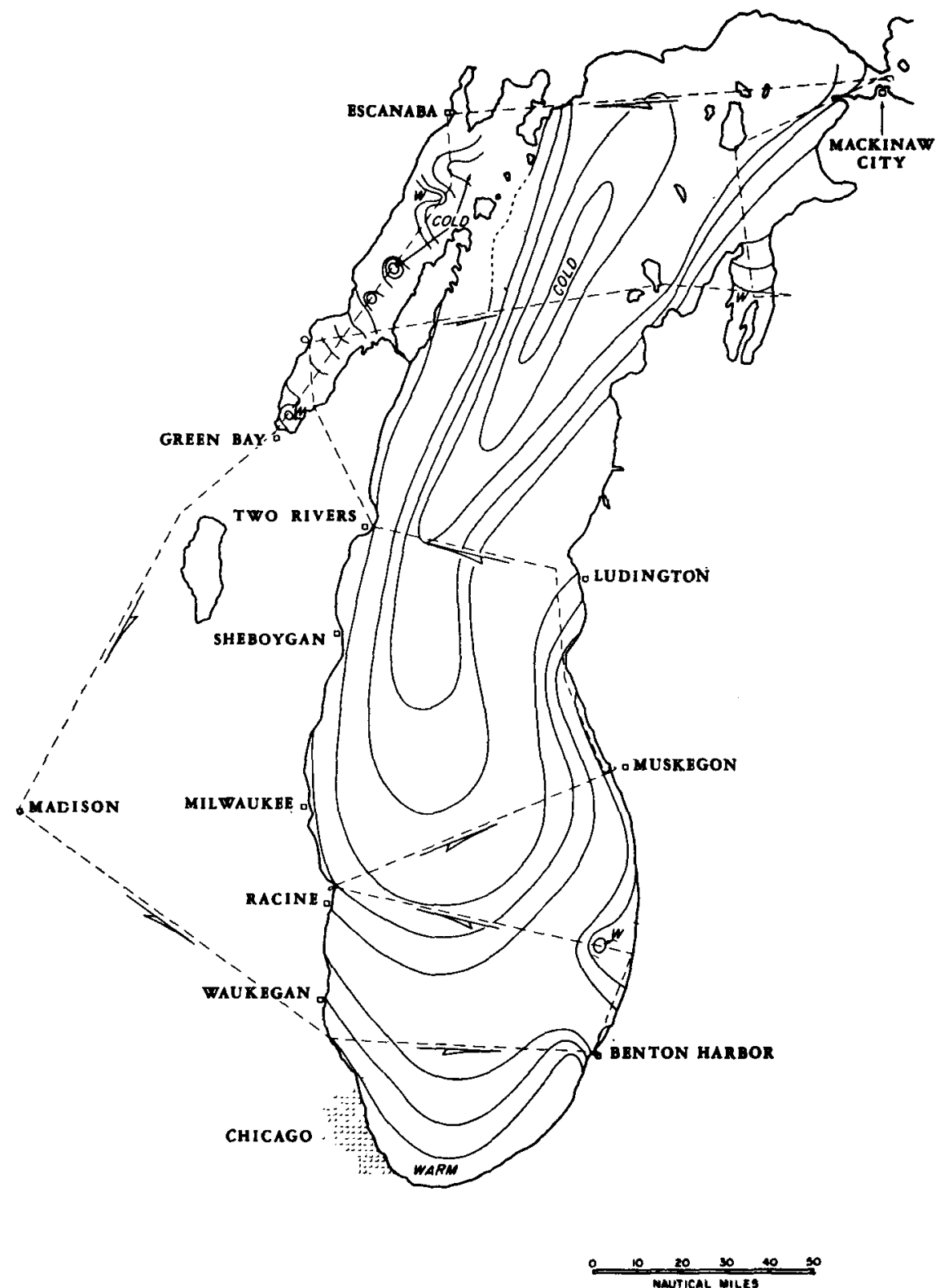

FIG. 2. Lake Michigan surface temperature distribution for July 1962 using $0.5 \mathrm{C}$ contour intervals (after McFadden and Ragotzkie, 1963). The dashed line indicates the aircraft flight path.

water, is used. During the warming-up and cooling-off seasons, the model lake is subjected to a surface temperature with a maximum or minimum at the center. The lake center is taken as the center of the Cartesian coordinates (Fig. 4). The $y$ coordinate is in the northsouth meridional direction. The lake is rotating with angular velocity $\Omega$ (component of the earth's rotation normal to the lake surface) about its vertical axis $z$, which is directed opposite to the gravitational force. The horizontal surface of the lake is considered free from wind stresses. Since the dominant flow is assumed to be meridional $(v$, north-south component of velocity q), the basic geostrophic thermal gradient relation can be satisfied.

The equations governing the steady mean motion of an incompressible, viscous, heat-conducting, rotating fluid are:

$$
\begin{aligned}
\mathbf{q}^{\prime} \cdot \nabla^{\prime} \mathbf{q}^{\prime}+2 \Omega \times \mathbf{q}^{\prime}=-\frac{1}{\rho_{0}} \nabla^{\prime} p^{\prime} & -g \frac{\Delta \rho}{\rho_{0}} \mathbf{k} \\
& +\left(\nu_{h} \frac{\partial^{2}}{\partial x^{\prime 2}}+\nu_{v} \frac{\partial^{2}}{\partial z^{\prime 2}}\right) \mathbf{q}^{\prime}
\end{aligned}
$$

$\nabla^{\prime} \cdot \mathbf{q}^{\prime}=0$ 


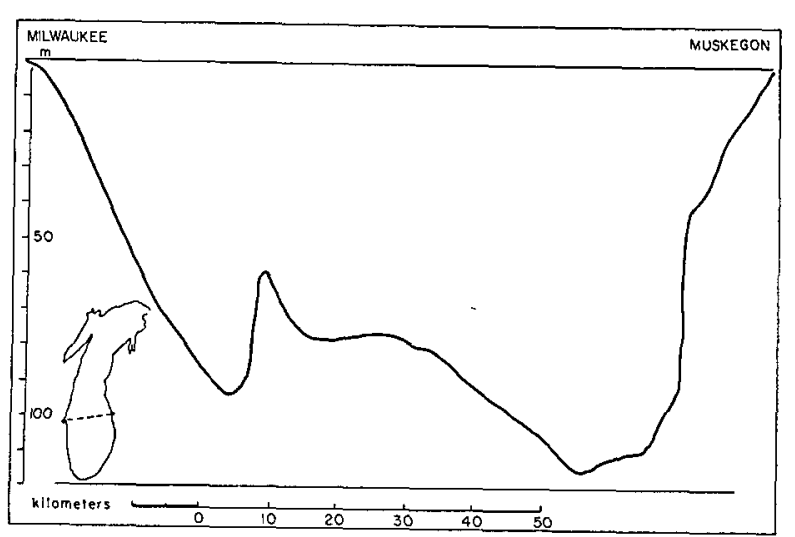

FIG. 3. East-west cross section of Lake Michigan between Milwaukee, Wis., and, Muskegon, Mich.

$$
\mathbf{q}^{\prime} \cdot \nabla^{\prime} T^{\prime}=\left(\kappa_{h} \frac{\partial^{2}}{\partial x^{\prime 2}}+\kappa_{v} \frac{\partial^{2}}{\partial z^{\prime 2}}\right) T^{\prime}
$$

In these relations the dependent variables are assumed independent of $y ; \nabla^{\prime}$ is a two-dimensional gradient operator and all primes are dimensional quantities. The average time period of the mean current is considered much shorter than the time period of seasonal temperature change. The quantity $\rho_{0}$ is the fluid density at reference temperature $T_{0}=4 \mathrm{C}, \Delta \rho$ is the density difference between density at temperature $T$ and $\rho_{0}$, while $\nu$ and $k$ are the kinematic eddy viscosity and the thermometric eddy diffusivity respectively. Since the horizontal eddy viscosity (or diffusivity) and the vertical eddy viscosity (or diffusivity) are of very different orders of magnitude, we distinguish these by subscripts " $h$ " and " $v$ ". They are treated crudely as constant.

The Boussinesq approximation is used in the formulation. Since the largest horizontal dimension of the lake is much smaller than the radius of the earth, curvature effects can be neglected. In the energy equation, the dissipation term is considered as small and therefore neglected.

The boundary conditions for the velocity field are the no-slip conditions at rigid surfaces, the bottom and the slant side boundaries, and the condition of zero stress and zero normal component of velocity at the free surface. The latter is assumed to be plane and horizontal.

The temperature boundary conditions are that the surface temperature distribution is a concave cosine profile during the warming-up season and a convex profile during the cooling-off season, and that the bottom temperature is very stable at $4 \mathrm{C}$. As to the slant side boundaries, the insulation conditions are imposed on the vertical planes at two edges which permit some conduction through the slant boundaries. This makes the boundary conditions similar to the real situation in the lake.

The equation of state is approximated as

$$
\rho^{\prime}=\rho_{0}\left[1-\alpha\left(T^{\prime}-T_{0}\right)\right],
$$

where $\alpha$, the coefficient of thermal expansion, is qualitatively treated as a constant. This approximation is valid as long as the temperature in the lake is all above or all below the temperature of maximum density of water. The special case of temperature distribution when the lake is partially above and partially below $4 \mathrm{C}$, will be studied later.

In terms of the lake width $L$ and depth $D$, the velocity scale $V$ has been deduced from the basic thermal wind relation as

$$
V=\frac{\alpha g D \Delta T}{2 \Omega L}
$$

where $g$ is the gravitational acceleration and $\Delta T$ is the total temperature difference $\left(T-T_{0}\right)$. The unprimed nondimensional variables are defined by

$$
\left.\begin{array}{rl}
x & =\frac{x^{\prime}}{L}, \quad z=\frac{z^{\prime}}{D}, \quad T=\frac{T^{\prime}-T_{0}}{\Delta T} \\
(u, v) & =\frac{1}{V}\left(u^{\prime}, v^{\prime}\right), \quad w=\frac{L w^{\prime}}{D V}, \quad p=\frac{p^{\prime}}{\left(\rho_{0} \alpha g D \Delta T\right)}
\end{array}\right\} .
$$

When we consider the mixing effect of vertical transport as being of the same order as the lateral mixing effect, the ratio of the horizontal eddy viscosity to that of the vertical eddy viscosity has the same value as the

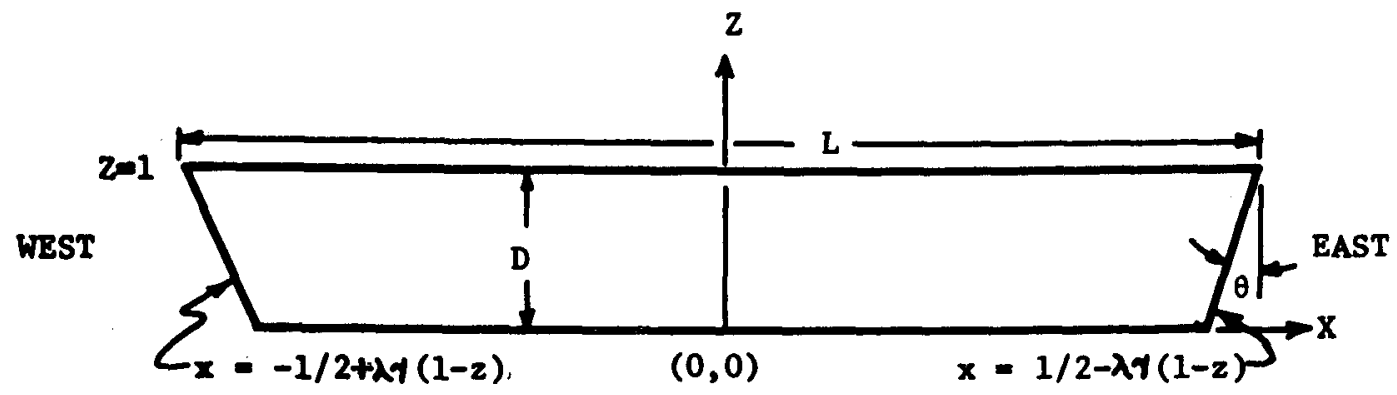

FIG. 4. Cross section of a long, symmetrical, trapezoidal Lake Michigan model. 
ratio of the reference length $L$ to the reference depth $D$; this agrees well with in situ measurements, (Csanady, 1964; Okubo and Farlon, 1967; Huang, 1968).

After introducing a streamfunction $\psi$ by defining

$$
\mathbf{q}=\mathbf{j} \times \nabla \psi(x, z)+\mathbf{j} v
$$

the nondimensional governing equations and boundary conditions for the warming-up season are:

$$
\begin{aligned}
& \epsilon \mathcal{L} \psi+\frac{\partial v}{\partial z}-\frac{\partial T}{\partial x}=\mathrm{R}\left[\frac{\partial \psi}{\partial z} \frac{\partial^{3} \psi}{\partial x \partial z^{2}}-\frac{\partial \psi}{\partial x} \frac{\partial^{3} \psi}{\partial z^{3}}\right.\left.-\gamma^{2}\left(\frac{\partial \psi}{\partial x} \frac{\partial^{3} \psi}{\partial x^{2} \partial z}-\frac{\partial \psi}{\partial z} \frac{\partial^{3} \psi}{\partial x^{3}}\right)\right] \\
& \epsilon \nabla^{2} v-\frac{\partial \psi}{\partial z}=\mathrm{R}\left(\frac{\partial \psi}{\partial z} \frac{\partial v}{\partial x}-\frac{\partial \psi}{\partial x} \frac{\partial v}{\partial z}\right) \\
& \epsilon \nabla^{2} T=\sigma \mathrm{R}\left(\frac{\partial \psi}{\partial z} \frac{\partial T}{\partial x}-\frac{\partial \psi}{\partial x} \frac{\partial T}{\partial z}\right)
\end{aligned}
$$

with the boundary conditions:

$$
\begin{aligned}
& \psi=\mathbf{q}=0, \quad T=0 \text { at } z=0 \\
& \psi=\frac{\partial^{2} \psi}{\partial z^{2}}=\frac{\partial v}{\partial z}=0, \quad T=\frac{1}{2}(1-\cos 2 \pi x) \text { at } z=1 \\
& \psi=\mathbf{q}=0 \text { on the slant boundaries and } \\
& \frac{\partial T}{\partial x}=0 \text { at } x= \pm \frac{1}{2}
\end{aligned}
$$

In the above

$$
\begin{aligned}
\gamma & =\frac{D}{L} \\
\mathcal{L} & =\gamma^{2} \frac{\partial^{4}}{\partial x^{4}}+(\gamma+1) \frac{\partial^{4}}{\partial x^{2} \partial z^{2}}+\frac{1}{\gamma} \frac{\partial^{4}}{\partial z^{4}} \\
\nabla^{2} & =\frac{\partial^{2}}{\partial x^{2}}+\frac{1}{\gamma} \frac{\partial^{2}}{\partial z^{2}}
\end{aligned}
$$

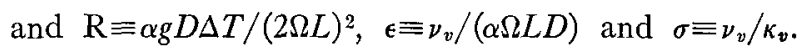
The latter three quantities are, respectively, the thermal Rossby number, the Ekman number, and the Prandtl number. Note that $\epsilon$ is similar to the reciprocal of the square root of the Taylor number and that $\sigma$ is of order unity.

\section{Analytic approximate solutions}

The governing Eqs. (5), (6) and (7), together with their boundary conditions (8), form a high-order, coupled, nonlinear system. Exact analytic solutions are very difficult to obtain. Therefore, approximate methods must be used (Robinson, 1959; Greenspan, 1968). Since $R \ll 1$, as found in the Lake Michigan model, we can easily see that the limiting case of (5) is that of a geostrophic thermal gradient balance, which is the basic assumption of the modeling. This suggests the method of regular perturbation by expanding all dependent variables in powers of $R$ as

$$
f(x, z)=\sum_{n=0}^{\infty} \mathrm{R}^{n} f^{(n)}(x, z)
$$

where the superscript denotes the order in $\mathrm{R}$.

The expansion of temperature in a power series in $\mathrm{R}$ needs justification. From the energy equation (7), since $\sigma$ is of order unity, $\mathrm{R}$ totally determines the relative importance of the heat conduction or the heat convection. Small $R$ means heat convection is relatively unimportant. However, the Ekman number $\epsilon$ is also a smaller number. At first sight, it seems from (7) that the temperature gradient terms coupled with momentum advections cannot be neglected even in the lowest order of approximation because the combination of these three parameters $(\sigma \mathrm{R} / \epsilon)$ is apparently not a small parameter. Nevertheless, due to the anisotropy of the induced meridional and vertical velocity field, the series expansion in powers of $\mathrm{R}$ for the temperature is valid everywhere in the flow field. Because the free surface boundary conditions force the streamfunction to be small, of order $\epsilon$ throughout the field, this makes heat convection as represented by the right-hand side of (7) still of order $\mathrm{R}$. At the boundaries the contribution due to the velocity-coupled heat convection is still small, even smaller than that in the interior region. Hence, the relative unimportance of the coupled heat convection is made clear. Actually, as will become obvious later, leading terms of every order of the $R$ expansion of temperature are of order unity. The expansion of temperature in powers of $\mathrm{R}$ is at least apparently asymptotic.

After employing expansions of the form (9) in (5)(7), and equating each power of $\mathrm{R}$, we find for the zeroth R-order equations

$$
\begin{aligned}
\epsilon \mathcal{L} \psi^{(0)}+\frac{\partial v^{(0)}}{\partial z}-\frac{\partial T^{(0)}}{\partial x} & =0 \\
\epsilon \nabla^{2} v^{(0)}-\frac{\partial \psi^{(0)}}{\partial z} & =0 \\
\nabla^{2} T^{(0)} & =0
\end{aligned}
$$

Notice that the zeroth $\mathrm{R}$-order temperature is controlled entirely by conduction.

$$
{ }_{n} T(1)=0 \quad \text { L } L^{i}
$$


(1)

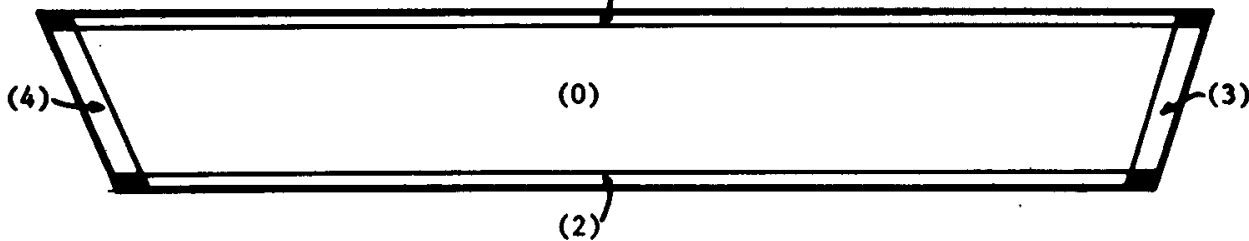

FIG. 5. Interior and boundary layer regions of the Lake Michigan model : 0 , the interior region; 1 , the surface region; 2 , the bottom region; 3 , the eastern boundary region; 4 , the western boundary region; corner areas are shaded.

The first $\mathrm{R}$-order equations are:

$$
\begin{aligned}
& \epsilon \mathcal{L} \psi^{(1)}+\frac{\partial v^{(1)}}{\partial z}-\frac{\partial T^{(1)}}{\partial x}=\left[\frac{\partial \psi^{(0)}}{\partial z} \frac{\partial^{3} \psi^{(0)}}{\partial x \partial z^{2}}-\frac{\partial \psi^{(0)}}{\partial x} \frac{\partial^{3} \psi^{(0)}}{\partial z^{3}}\right. \\
& \left.-\gamma^{2}\left(\frac{\partial \psi^{(0)}}{\partial x} \frac{\partial^{3} \psi^{(0)}}{\partial z \partial x^{2}}-\frac{\partial \psi^{(0)}}{\partial z} \frac{\partial^{3} \psi^{(0)}}{\partial x^{3}}\right)\right], \\
& \epsilon \nabla^{2} v^{(1)}-\frac{\partial \psi^{(1)}}{\partial z}=\frac{\partial \psi^{(0)}}{\partial z} \frac{\partial v^{(0)}}{\partial x}-\frac{\partial \psi^{(0)}}{\partial x} \frac{\partial v^{(0)}}{\partial z}, \\
& \epsilon \nabla^{2} T^{(1)}=\sigma\left(\frac{\partial \psi^{(0)}}{n} \frac{\partial T^{(0)}}{n}-\frac{\partial \psi^{(0)}}{n} \frac{\partial T^{(0)}}{n}\right)
\end{aligned}
$$

is approximately valid for all $\mathrm{R}$-order equations. The local coordinates in the boundary regions are deduced from (18) with the normal coordinates stretched as shown in Table 1. The boundary layer thicknesses are $\epsilon_{1}^{\frac{1}{3}}$ for the upper and the lower boundaries and $\epsilon_{2}^{\frac{1}{2}}$ for the slant side boundaries. Note that $\epsilon_{1}=\epsilon / \gamma, \epsilon_{2}=\epsilon K$, where

$$
K=\left[\frac{1}{\lambda^{2}}+2(\gamma+1)+\left(1+\frac{2}{\gamma}\right) \lambda^{2} \gamma^{2}+\lambda^{4} \gamma^{2}\right]^{\frac{1}{2}}, \quad \lambda=\tan \theta
$$

as indicated in Fig. 4.

As expected in the boundary layer problem, stretching the nommol monedinates of their resenertive houndaries where

$$
\begin{aligned}
& { }_{1} v^{(0)}=-\epsilon_{1^{\frac{3}{2}}} \frac{\pi}{2^{\frac{3}{2}}} e^{-\zeta_{1} / 2^{\frac{1}{3}}} \sin 2 \pi x\left(\cos \frac{\zeta_{1}}{2^{\frac{1}{2}}}-\sin \frac{\zeta_{1}}{2^{\frac{1}{2}}}\right), \\
& { }_{2} v^{(0)}=\epsilon_{1}^{\frac{3}{2} 2^{\frac{3}{2}}} \pi e^{-\zeta 2 / 2^{\frac{3}{3}}} \sin 2 \pi x \cos \frac{\zeta_{2}}{2^{\frac{1}{2}}}, \\
& i^{(0)}= \pm\left\{\frac{1-\cosh a \eta_{i}}{2 \gamma^{\frac{3}{2}} H}\right. \\
& \left.+\epsilon^{\frac{1}{2}} 2^{\frac{1}{2}} \pi\left[\frac{1}{\gamma^{\frac{1}{2}}} \mp \frac{\lambda K^{\frac{1}{3}}}{\left(1+\lambda^{2} \gamma\right)}\left(1-e^{ \pm \xi_{i} / 2 \frac{1}{3}} \cos \frac{ \pm \xi_{i}}{2^{\frac{1}{2}}}\right)\right]\right\} \\
& \times \sin 2 \pi \lambda \gamma\left(1-\eta_{i}\right), \quad i=3,4 \text {; }
\end{aligned}
$$

and

$$
\begin{aligned}
& { }_{1} v^{(0)}=0 \text {, } \\
& { }_{2} v^{(1)}=\epsilon_{1}^{\frac{\pi^{2}}{2}} \frac{{ }^{2}(1-G)}{2 \gamma H} e^{-\zeta_{2} / 2 \xi} \sin 4 \pi x \cos \frac{\zeta_{2}}{2^{\frac{1}{3}}}, \\
& { }_{i} v^{(1)}=\mp \epsilon_{2}{ }^{2} \frac{\pi^{2} \lambda e^{ \pm \zeta_{i} / 2}}{2 \cdot \gamma H\left(1+\lambda^{2} \gamma\right)} \sin 4 \pi \lambda \gamma\left(1-\eta_{i}\right) \\
& \times \cos \frac{\zeta_{1}}{2^{\frac{1}{2}}}\left(\cosh a \eta_{i}-G\right) \pm h\left(\eta_{i}\right), \quad i=3,4 ;
\end{aligned}
$$

finally,

$$
h\left(\eta_{i}\right)=--\left[\frac{\sinh a \eta_{i}}{\cdot}-2 \pi \eta_{i}+\frac{(G-1)}{---}\left(1-\cosh a \eta_{i}\right)\right]
$$

\section{a. Types of circulation patterns}

During the winter cooling period, when the whole lake is below $4 \mathrm{C}$ and both edges of the lake are colder than the middle, the surface temperature profile is in the form of a cosine function with its maximum, slightly less than $4 \mathrm{C}$, at the middle. The current circulation induced in our model during this period, however, has the same pattern as in the summer heating period, when the surface temperature in the lake is above $4 \mathrm{C}$ and the edges have much higher temperatures than the middle. The fact that the same circulation patterns are induced by these two imposed temperature forms is due to the combination effects of the special characteristics of the fresh water density and of the change in direction of the thermal gradient during the heating and the cooling periods. This type of circulation pattern is called type A circulation. The mathematical demonstration of the type A circulation pattern has been shown in the previous section. Another type of circulation, called the type $B$ circulation pattern, is expected to exist during the period of autumn cooling when the whole lake is still above $4 \mathrm{C}$ with the two edges at a lower temperature near $4 \mathrm{C}$, and during the period of spring heating when the whole lake is below $4 \mathrm{C}$ with the edges in a bit warmer state at nearly $4 \mathrm{C}$. The type $\mathrm{B}$ circulation is the exact opposite pattern of the type A circulation except that the magnitudes may be slightly smaller due to the counter effect of the existence of a northsouth thermal gradient.

\section{b. Physical parameters}


have been obtained. In the boundary regions, (15) becomes an ordinary differential equation of the local coordinates. Boundary layer solutions can be obtained easily by integrations. In the interior region (15) can be solved by allowing the particular solution, together with (8), to become the new boundary conditions. Higher R-order solutions may be obtained in a similar manner. The total temperature distribution is

$$
\begin{aligned}
& T=\frac{1}{2}[z\left.-\frac{\sinh a z}{H} \cos 2 \pi x\right] \\
&+\mathrm{R} \sigma\left\{\frac{\pi}{4 H \gamma^{\frac{1}{2}}}[\cosh a z-1+(1-G) z]\right. \\
&+\frac{1}{4 \gamma}\left[1-\cosh a z+\frac{(G-1)}{H} \sinh a z\right] \cos 2 \pi x \\
&+\frac{\pi}{12 \gamma^{\frac{1}{2}} H}[\cosh 2 a z-\cosh a z \\
&\left.\left.+\frac{G-G_{2}}{H_{2}} \sinh 2 a z\right] \cos 4 \pi x+T^{(1)}\right\} \\
&+\mathrm{O}\left(\mathrm{R}^{2}\right), \quad j=1,2,3,4,
\end{aligned}
$$

where

$$
\begin{aligned}
& { }_{1} T^{(1)}=\epsilon_{1^{\frac{2}{2}}} \frac{\pi^{2}}{2^{\frac{1}{2}}} \sin ^{2} 2 \pi x\left[1-\exp \left(-\frac{\zeta_{1}}{2^{\frac{1}{2}}}\right)\left(\cos \frac{\zeta_{1}}{2^{\frac{1}{2}}}-\sin \frac{\zeta_{1}}{2^{\frac{1}{2}}}\right)\right], \\
& { }_{2} T^{(1)}=0, \\
& { }_{i} T^{(1)=} \boldsymbol{\epsilon}_{2^{\frac{3}{2}}} \frac{\pi \sin 2 \pi \lambda \gamma\left(1-\eta_{i}\right)}{2^{\frac{1}{2}}\left(1+\lambda^{2} \gamma\right) \gamma} \\
& \times\left[1+\frac{a \cosh a \eta_{i}}{H} \cos 2 \pi \lambda \gamma\left(1-\eta_{i}\right)\right. \\
& \left. \pm \frac{2 \pi \lambda \gamma}{H} \sinh a \eta_{i} \sin 2 \pi \lambda \gamma\left(1-\eta_{i}\right)\right] \\
& \quad \times\left[\exp \left( \pm \frac{\xi_{i}}{2^{\frac{1}{2}}}\right) \cos \frac{\xi_{i}}{2^{\frac{1}{2}}}-1\right], \quad i=3,4
\end{aligned}
$$

(whenever $i=3$, use the upper sign; when $i=4$, use the lower sign) and $a \equiv 2 \pi \gamma^{\frac{1}{2}}, H \equiv \sinh 2 \pi \gamma^{\frac{1}{2}}, G \equiv \cosh 2 \pi \gamma^{\frac{1}{2}}$, $H_{2} \equiv \sinh 4 \pi \gamma^{\frac{1}{2}}, G_{2} \equiv \cosh 4 \pi \gamma^{\frac{1}{2}}$. We notice that the leading terms for each $\mathrm{R}$-order temperature are $\mathrm{O}(1)$. Therefore, the asymptotic character of the series expansion is now plausible.

\section{b. Velocity field}

Accordingly, the streamfunction can be obtained by solving the coupled equations (11), (14), (18), and the meridional velocity can be obtained by solving (10), (11), (13), (14), and a similar equation like (18), together with all respective boundary conditions indicated in (8). The resultant streamfunction is

$\psi=\epsilon_{1} \pi \sin 2 \pi x+{ }_{j} \psi^{(0)}$

$$
\begin{array}{r}
+\mathrm{R}\left[\frac{\epsilon_{1} \pi^{2}}{2 H \gamma^{3}} \sin 4 \pi x(\cosh a z-G)+{ }_{j} \psi^{(1)}\right] \\
+\mathrm{O}\left(\mathrm{R}^{2}\right), \quad j=1,2,3,4
\end{array}
$$

where

$$
\begin{aligned}
& { }_{1} \psi^{(0)}=-\epsilon_{1} \pi \exp \left(-\frac{\zeta_{1}}{2^{\frac{1}{2}}}\right) \sin 2 \pi x \cos \frac{\zeta_{1}}{2^{\frac{1}{2}}}, \\
& { }_{2} \psi^{(0)}=-\epsilon_{1} \pi \exp \left(\frac{-\zeta_{2}}{2^{\frac{1}{2}}}\right) \sin 2 \pi x\left(\cos \frac{\zeta_{2}}{2^{\frac{1}{2}}}+\sin \frac{\zeta_{2}}{2^{\frac{1}{i}}}\right), \\
& { }_{i} \psi^{(0)}=-\epsilon_{1} \pi \sin 2 \pi \lambda \gamma\left(1-\eta_{i}\right) \\
& \quad \times \exp \left( \pm \frac{\xi_{i}}{2^{\frac{1}{2}}}\right)\left(\cos \frac{\xi_{i}}{2^{\frac{1}{2}}} \pm \sin \frac{\xi_{i}}{2^{\frac{1}{2}}}\right), \quad i=3,4,
\end{aligned}
$$

and

$$
\begin{aligned}
& { }_{1} \psi^{(1)}=0 \\
& { }_{2} \psi^{(1)}=-\epsilon_{1} \frac{\pi^{2}(1-G)}{2 H \gamma^{\frac{1}{2}}} \exp \left(\frac{-\zeta_{2}}{2^{\frac{1}{2}}}\right) \sin 4 \pi x\left(\cos \frac{\zeta_{2}}{2^{\frac{1}{2}}}+\sin \frac{\zeta_{2}}{2^{\frac{1}{2}}}\right) \\
& { }_{i} \psi^{(1)}= \pm \epsilon_{1} \frac{\pi^{2}}{2 H \gamma^{\frac{1}{2}}} \exp \left( \pm \frac{\xi_{i}}{2^{\frac{1}{2}}}\right) \sin 4 \pi \lambda \gamma\left(1-\eta_{i}\right) \\
& \times\left(\cosh a \eta_{i}-G\right)\left(\cos \frac{\xi_{i}}{2^{3}} \pm \sin \frac{\xi_{i}}{2^{\frac{1}{2}}}\right), \quad i=3,4 .
\end{aligned}
$$

The total meridional velocity is found, without details, to be

$$
\begin{aligned}
v= & \left(\frac{\cosh a z-1}{2 \gamma^{\frac{1}{2}} H}-\epsilon_{\left.1^{\frac{1}{2}} 2^{\frac{1}{2}} \pi\right) \sin 2 \pi x+j_{j}(0)}\right. \\
& +\mathrm{R}\left\{\frac{\sigma}{4 \gamma}-\left[\frac{\sinh a z}{\gamma^{\frac{1}{2}}}-2 \pi z+\frac{(G-1)}{\gamma^{\frac{1}{2}} H}(1-\cosh a z)\right] \sin 2 \pi x\right. \\
& -\left[\frac{\sigma \pi}{6 \gamma H}\left(\frac{\sinh 2 a z}{2}-\sinh a z+\frac{\left(G-G_{2}\right)}{2 H_{2}}(\cosh 2 a z-1)\right)\right. \\
& \left.\left.-\epsilon_{1}^{\frac{3}{2}} \frac{\pi^{2}(1-G)}{2^{\frac{1}{2}} \gamma H}\right] \sin 4 \pi x+{ }_{j}^{(1)}\right\}+\mathrm{O}\left(\mathrm{R}^{2}\right),
\end{aligned}
$$


where

$$
\begin{aligned}
& { }_{1} v^{(0)}=-\epsilon_{1}^{\frac{1}{2}} \frac{\pi}{2^{\frac{1}{2}}} e^{-\zeta_{1} / 2 \frac{1}{2}} \sin 2 \pi x\left(\cos \frac{\zeta_{1}}{2^{\frac{1}{2}}}-\sin \frac{\zeta_{1}}{2^{\frac{1}{2}}}\right),
\end{aligned}
$$

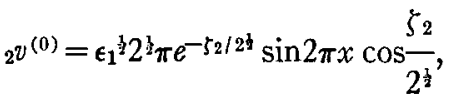

$$
\begin{aligned}
& i^{(0)}= \pm\left\{\frac{1-\cosh a \eta_{i}}{2 \gamma^{\frac{1}{2}} H}\right. \\
& \left.+\epsilon^{\frac{1}{2}} 2^{\frac{1}{2}} \pi\left[\frac{1}{\gamma^{\frac{1}{2}}} \mp \frac{\lambda K^{\frac{1}{2}}}{\left(1+\lambda^{2} \gamma\right)}\left(1-e^{ \pm \xi_{i} / 2^{\frac{1}{t}}} \cos \frac{ \pm \xi_{i}}{2^{\frac{1}{2}}}\right)\right]\right\} \\
& \times \sin 2 \pi \lambda \gamma\left(1-\eta_{i}\right), \quad i=3,4 ;
\end{aligned}
$$

and

$$
\begin{aligned}
& { }_{1} v^{(0)}=0,
\end{aligned}
$$

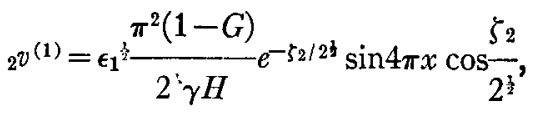

$$
\begin{aligned}
& i_{i}^{(1)}=\mp \epsilon_{2} \cdot \frac{\pi^{2} \lambda e^{ \pm \zeta i / 2}}{2 \vdots H\left(1+\lambda^{2} \gamma\right)} \sin 4 \pi \lambda \gamma\left(1-\eta_{i}\right) \\
& \times \cos \frac{\zeta_{1}}{2}\left(\cosh a \eta_{i}-G\right) \pm h\left(\eta_{i}\right), \quad i=3,4 ;
\end{aligned}
$$

finally,

$$
\begin{gathered}
h\left(\eta_{i}\right)=\frac{\sigma}{4 \gamma}\left[\frac{\sinh a \eta_{i}}{\gamma^{\frac{1}{2}}}-2 \pi \eta_{i}+\frac{(G-1)}{\gamma^{1} H}\left(1-\cosh a \eta_{i}\right)\right] \\
\times \sin \pi \lambda \gamma\left(1-\eta_{i}\right) \\
+\left\{\frac{\sigma \pi}{4 \gamma H}\left[\frac{\sinh 2 a \eta_{i}}{2}-\sinh a \eta_{i}+\frac{G-G_{2}}{2 H}\left(\cosh 2 a \eta_{i}-1\right)\right]\right. \\
\left.+\epsilon_{1} \frac{\pi^{2}(1-G)}{2^{\frac{2}{3}} \gamma H}-\epsilon_{2}^{\frac{1}{2}} \frac{\pi^{2} \lambda}{2^{\frac{1}{2}} \gamma H\left(1+\lambda^{2} \gamma\right)}\left(\cosh a \eta_{i}-G\right)\right\} \\
\times \sin 4 \pi \lambda \gamma\left(1-\eta_{i}\right) .
\end{gathered}
$$

Note that all boundary layer solutions in our model study are weaker by $O\left(\epsilon^{\frac{1}{3}}\right)$ than those obtained in the case of a rigid surface (see, for example, Robinson, 1959). This agrees with Hide's (1964) result that the Ekman boundary layer associated with a free surface is weaker than that associated with a rigid surface.

\section{Discussion}

The surface temperature across the lake which is used as the free surface temperature boundary condition is a quasi-steady seasonal function of time. For simplicity, we have approximated it as a concave or convex cosine function for a specific season.

\section{a. Types of circulation patterns}

During the winter cooling period, when the whole lake is below $4 \mathrm{C}$ and both edges of the lake are colder than the middle, the surface temperature profile is in the form of a cosine function with its maximum, slightly less than $4 \mathrm{C}$, at the middle. The current circulation induced in our model during this period, however, has the same pattern as in the summer heating period, when the surface temperature in the lake is above $4 \mathrm{C}$ and the edges have much higher temperatures than the middle. The fact that the same circulation patterns are induced by these two imposed temperature forms is due to the combination effects of the special characteristics of the fresh water density and of the change in direction of the thermal gradient during the heating and the cooling periods. This type of circulation pattern is called type $\mathbf{A}$ circulation. The mathematical demonstration of the type A circulation pattern has been shown in the previous section. Another type of circulation, called the type $B$ circulation pattern, is expected to exist during the period of autumn cooling when the whole lake is still above $4 \mathrm{C}$ with the two edges at a lower temperature near $4 \mathrm{C}$, and during the period of spring heating when the whole lake is below $4 \mathrm{C}$ with the edges in a bit warmer state at nearly $4 \mathrm{C}$. The type $\mathrm{B}$ circulation is the exact opposite pattern of the type A circulation except that the magnitudes may be slightly smaller due to the counter effect of the existence of a northsouth thermal gradient.

\section{b. Physical parameters}

All physical parameters used for our theoretical model study in simulating the real phenomena in the lake are summarized in Table 2. All values of special parameters related to seasonal temperature changes are listed in Table 3 . Note that the coefficient of thermal expansion, $\alpha$, of fresh water is a function of local temperature. In Table 3 the coefficients of thermal expansion of fresh water at 11 and $3 \mathrm{C}$ are used as representative values. Note also that $\Delta T$ is in the positive (increasing) sense

TABLE 2. General physical data used in the Lake Michigan model.

\begin{tabular}{clc}
\hline \hline Parameter notation & \multicolumn{1}{c}{ Value } & Unit \\
\hline$L$ & $1.22 \times 10^{7}$ & $\mathrm{~cm}$ \\
$D$ & $1.22 \times 10^{4}$ & $\mathrm{~cm}$ \\
$2 \Omega$ & $10^{-4}$ & $\mathrm{rad} \mathrm{sec}^{-1}$ \\
$\nu_{v}$ & 30 & $\mathrm{~cm}^{2} \mathrm{sec}^{-1}$ \\
$\nu_{h}$ & $3 \times 10^{4}$ & $\mathrm{~cm}^{2} \mathrm{sec}^{-1}$ \\
$\lambda$ & $10^{2}$ & \\
$\epsilon$ & $2 \times 10^{-6}$ & \\
$\gamma$ & $10^{-3}$ & \\
$\sigma$ & 1 & \\
$K$ & 11 & \\
$\epsilon_{1}$ & $4 \times 10^{-3}$ & \\
$\epsilon_{2}$ & $4.4 \times 10^{-5}$ & \\
$g$ & 980 & $\mathrm{~cm} \mathrm{sec}$ \\
\end{tabular}


during the warm-up seasons and is in the negative (decreasing) sense during the cooling-off seasons.

\section{c. Temperature distribution}

Using the representative physical parameters in Tables 2 and 3 , the nondimensional temperature solution, (20), has been plotted as shown in Fig. 6 . During the summer-heating period, the isotherms in Fig. 6 are about $1 \mathrm{C}$ apart and increase shoreward. The autum-cooling period has the same temperature distribution as shown in Fig. 6, but the temperature decreases shoreward since $\Delta T$ is in the negative sense during the cooling-off season. For the other two periods of the year, i.e., the spring-heating and the winter-cooling seasons, the isotherms have the same form except that the magnitudes of the temperature differences are smaller.

The best way to verify a geophysical dynamic model is to compare the theoretical solutions with those of field observations. Church (1942a, b) made a comprehensive study of the annual temperature cycle of Lake Michigan in many cross sections of the lake. Figs. $7 \mathrm{a}-\mathrm{h}$ are Church's observed temperature distributions during different months of the year when the lake is quasihomogeneous, the dashed lines on the insert maps showing the transections and the vectors the local mean winds. Fig. 7a is the January temperature profile across the Milwaukee-Muskegon section of the lake (Church, 1942, Fig. 8), showing that the maximum surface temperature in the cross section is at $4 \mathrm{C}$ in the middle of the lake, with the temperature decreasing toward the shores. This is very similar to the temperature distribution obtained in our theoretical study during the wintercooling period discussed above, except that the former has a sharper temperature gradient near the shores. Figs. $7 \mathrm{~b}$ and $7 \mathrm{c}$ are Church's February and March temperatures. They all show very nearly the same distribution pattern as given by the theoretical study.

In late March or early April the edges of the lake have already warmed-up to a temperature $\gtrsim 4 \mathrm{C}$, as shown in Fig. 7d, which is Church's observed temperature distribution of mid-April. Fig. $7 d$ shows the characteristic temperature distribution of the springheating period which has the two edges of the lake at nearly $4 \mathrm{C}$ and the middle of the lake at a slightly lower

TABLE 3. Values of parameters related to temperature.

\begin{tabular}{|c|c|c|c|}
\hline \multirow{2}{*}{$\begin{array}{c}\text { Parameter } \\
\text { notation }\end{array}$} & \multicolumn{2}{|c|}{ Value } & Units \\
\hline & $\begin{array}{l}\text { Spring-heating and } \\
\text { autumn-cooling } \\
\text { periods }\end{array}$ & $\begin{array}{l}\text { Winter-cooling and } \\
\text { spring-heating } \\
\text { periods }\end{array}$ & \\
\hline $\begin{array}{l}\alpha \\
\Delta T \\
V \\
R\end{array}$ & $\begin{array}{l}2 \times 10^{-4} \\
10 \\
20 \\
1.65 \times 10^{-2}\end{array}$ & $\begin{array}{l}2 \times 10^{-5} \\
4 \\
1 \\
10^{-3}\end{array}$ & $\begin{array}{l}\left({ }^{\circ} \mathrm{C}\right)^{-1} \\
\left({ }^{\circ} \mathrm{C}\right) \\
\mathrm{cm} \mathrm{sec}^{-1}\end{array}$ \\
\hline
\end{tabular}

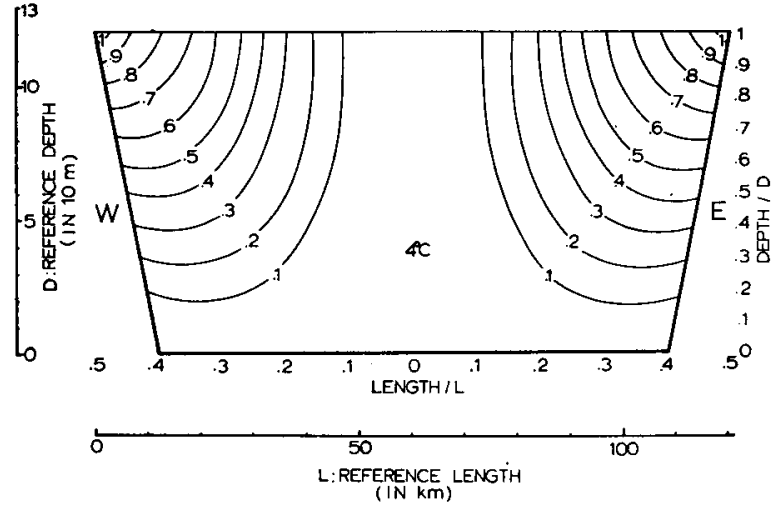

Fig. 6. Nondimensional temperature distribution in Lake Michigan model.

temperature. Figs. 7e and $7 \mathrm{f}$ show the observed temperature distributions of the summer-heating season. Qualitatively they agree well with our predictions. Notice from Fig. 7f that a thermocline starts to form after late June or early July. Not until the thermocline is very deep and weak in late November, as indicated in Fig. $7 \mathrm{~g}$, can the lake be again considered in a quasihomogeneous state. At that time the atmospheric temperature is already colder than the temperature of the lake. The observed December temperature, as shown in Fig. 7h, agrees with the autumn-cooling temperature distribution as indicated in Fig. 6 .

In general, the predicted temperature distributions of the theoretical model agree qualitatively very well with the observed field data. But the isotherms of the theoretical temperature solution are more widely spread and evenly distributed than those of the real data. This is because of the smoothed surface temperature profile we have used as boundary condition in solving the energy equation. Finally, it is obvious that the strongly stratified period of the lake is not included in the present study.

\section{d. Velocity field}

Under the basic assumption that the geostrophic and the thermal gradient forces are in equilibrium in the flow field, the meridional velocity $v$ dominates the circulation pattern. The nondimensional meridional velocity of the type-A circulation, given by (22), has been plotted in quasi-perspective form as shown in Fig. 8. In the upper half of the fluid in the Lake Michigan model, there is a northbound flow on the eastern part of the lake and a southbound flow on the western part. In the middle portion of the lake, the meridional velocity is very weak. It becomes stronger away from the center and reaches a maximum at about one-fourth of the lake width from the shores. It then decreases toward the shore but becomes strong again within the eastern and western boundary regions due to the reinforcement of the boundary layer currents near the slant side boundaries. 


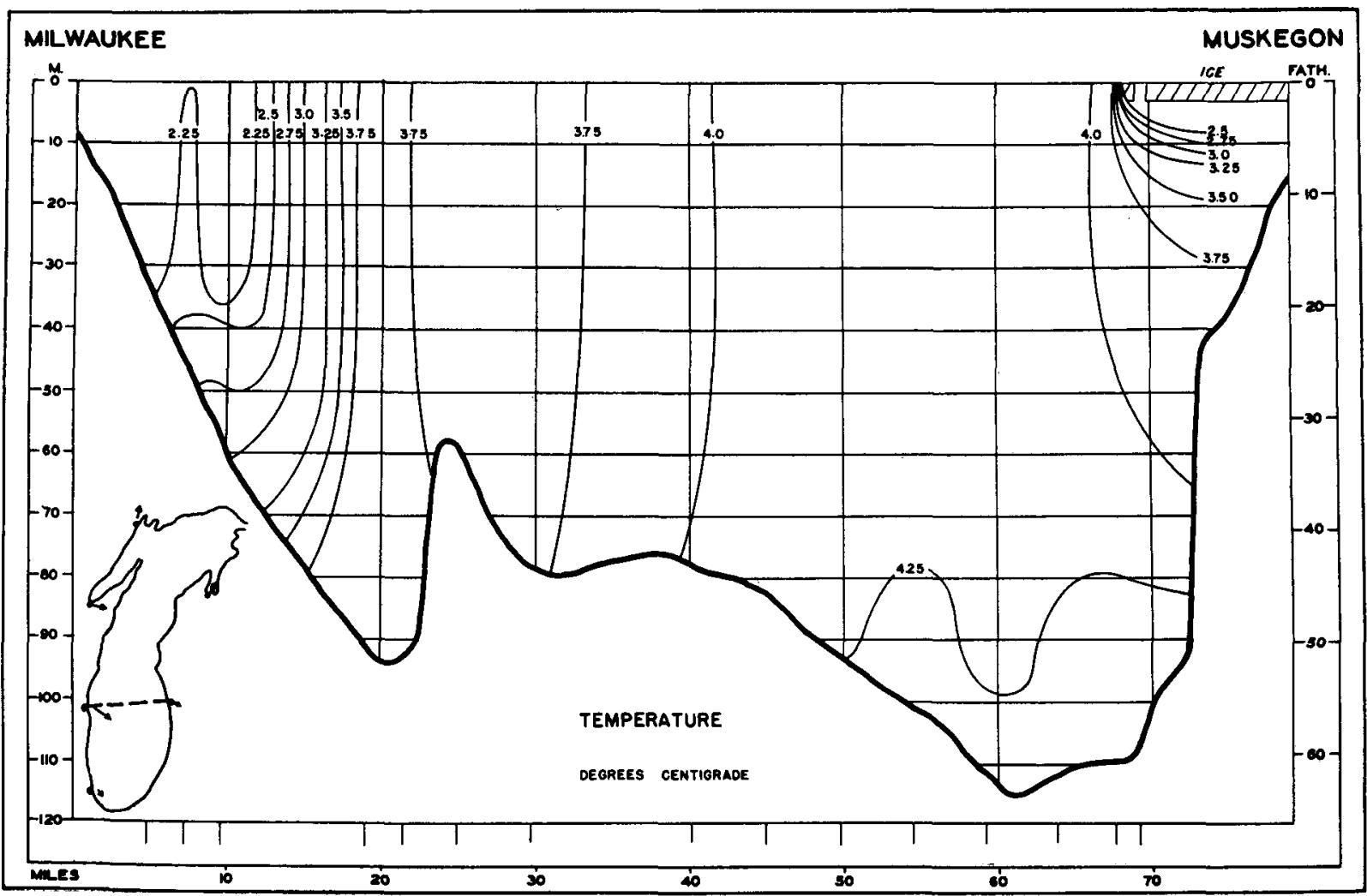

a. January

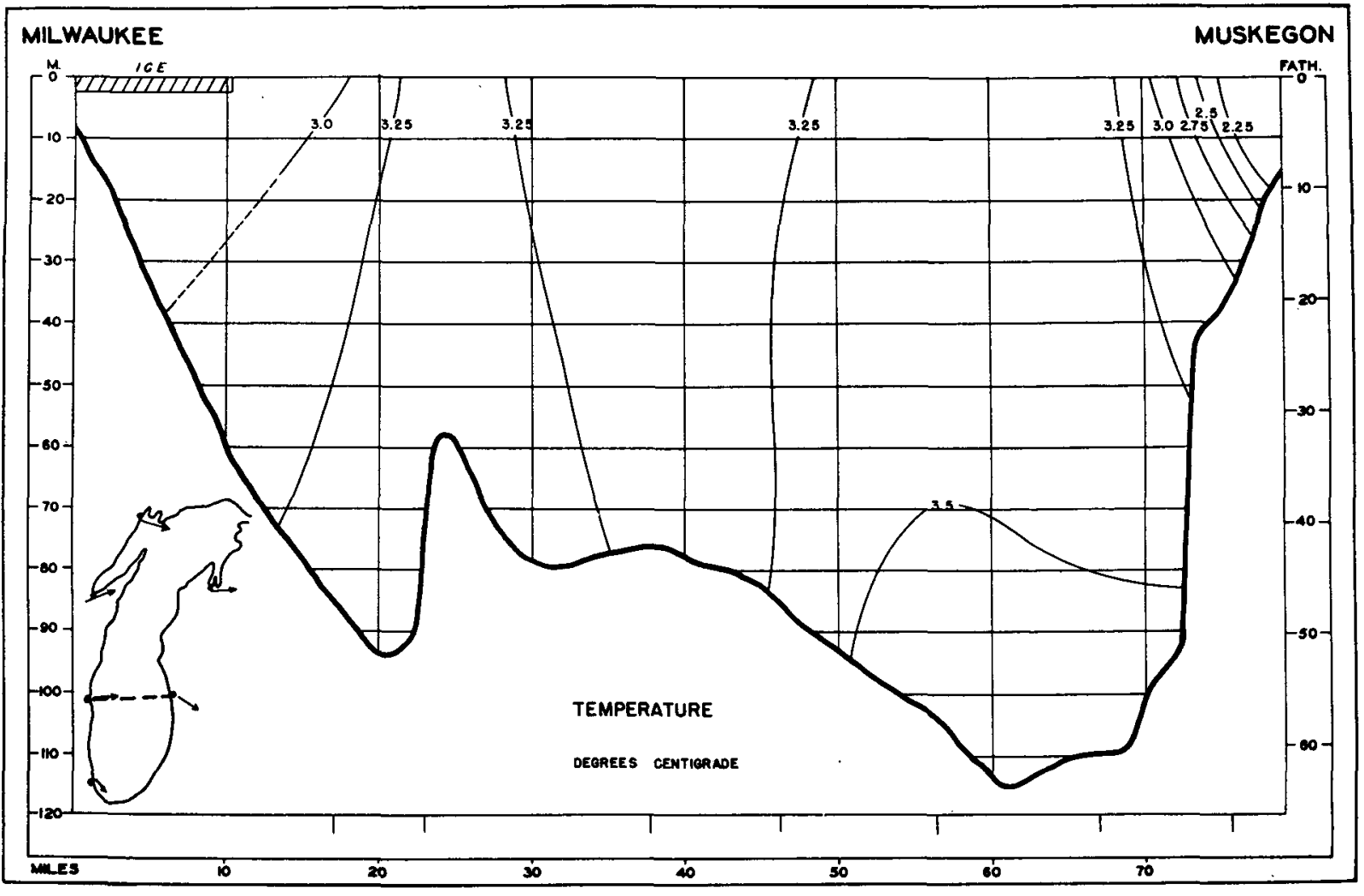

b. February

FIG. 7. Observed temperature distribution in Lake Michigan (after Church, 1942). The dashed line in the temperature field of $7 \mathrm{e}, 7 \mathrm{f}$ and $7 \mathrm{~g}$ represents the top and bottom limits of the thermocline. 


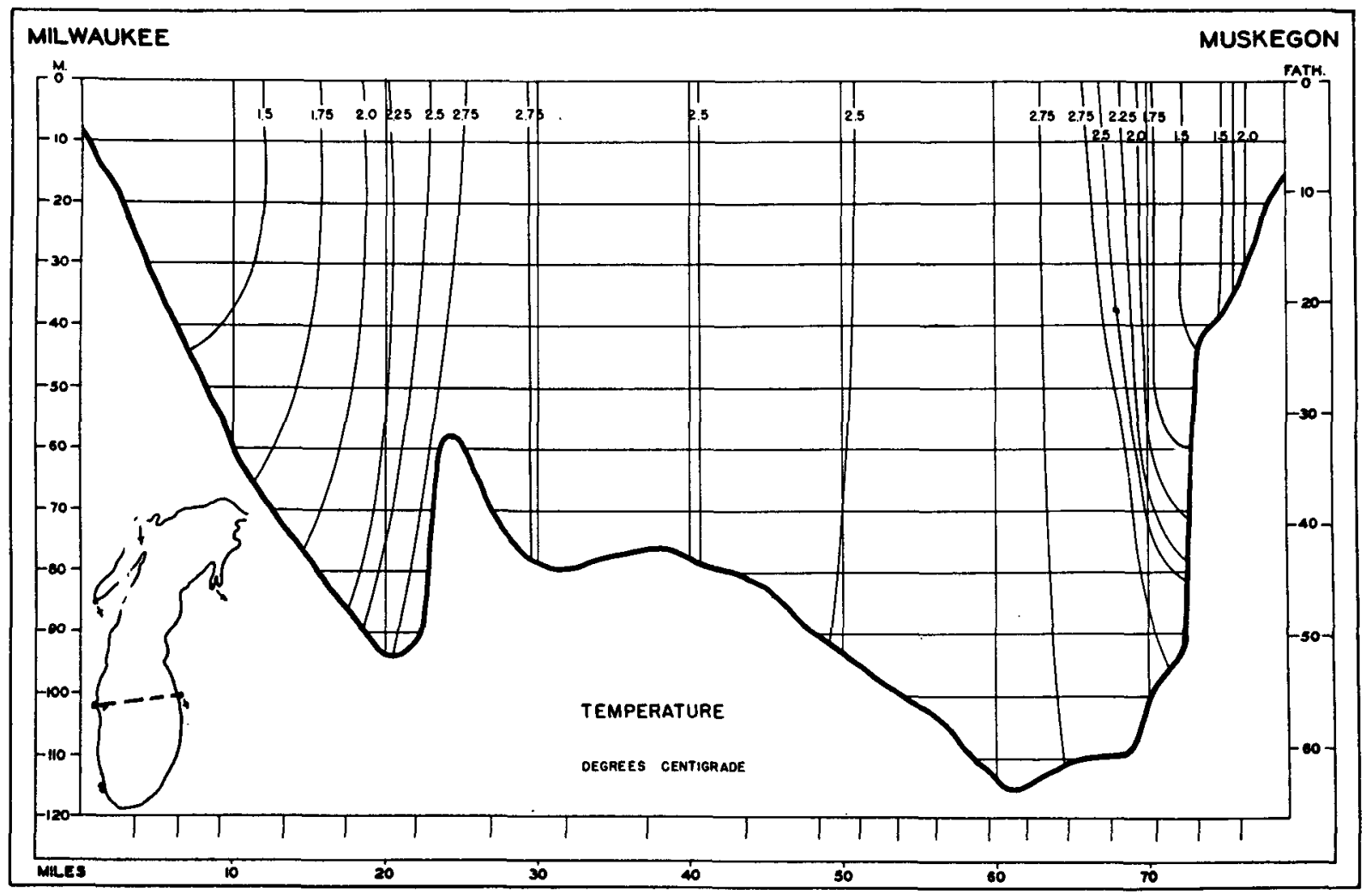

c. March

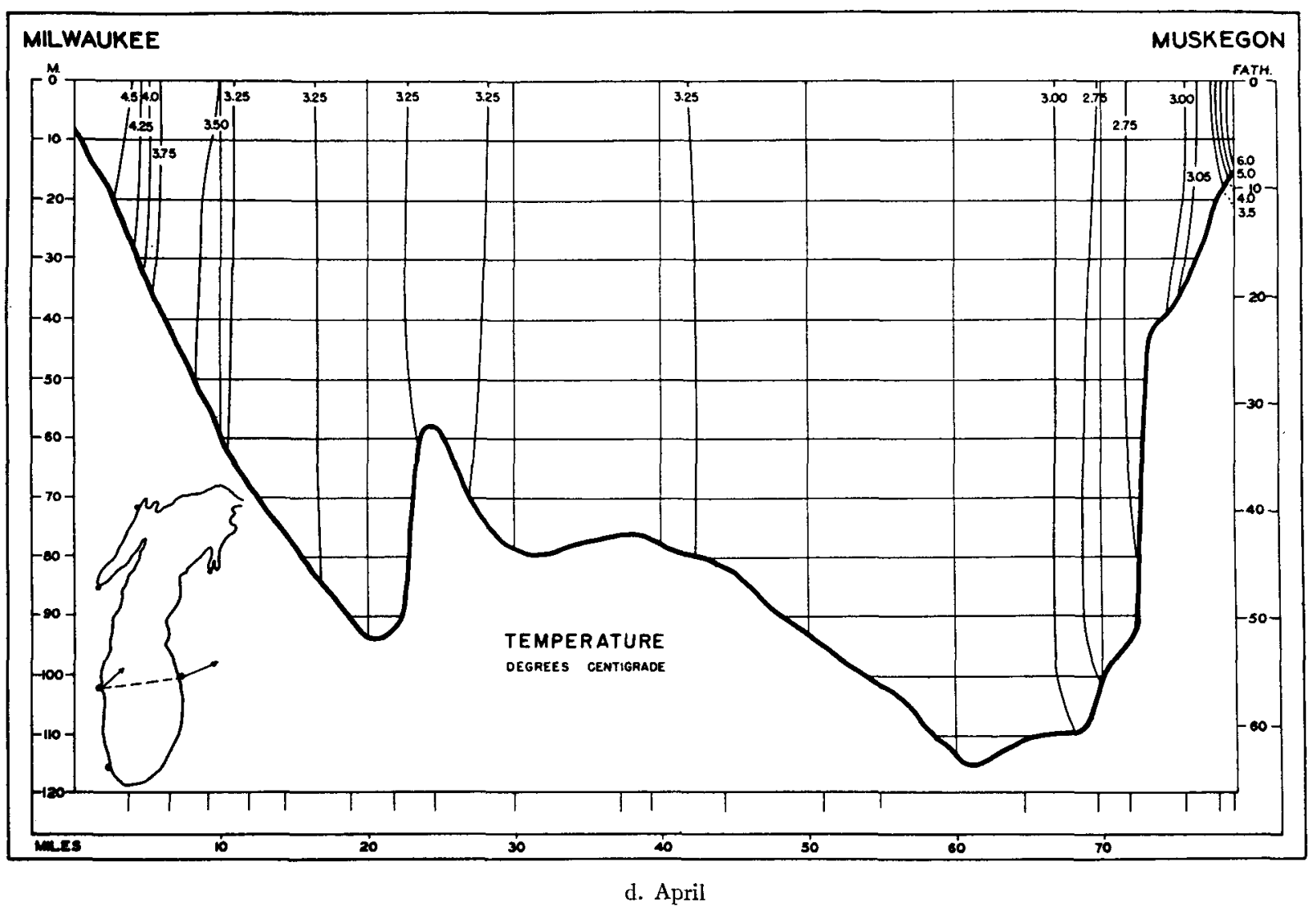

FIG. 7. (continued) 


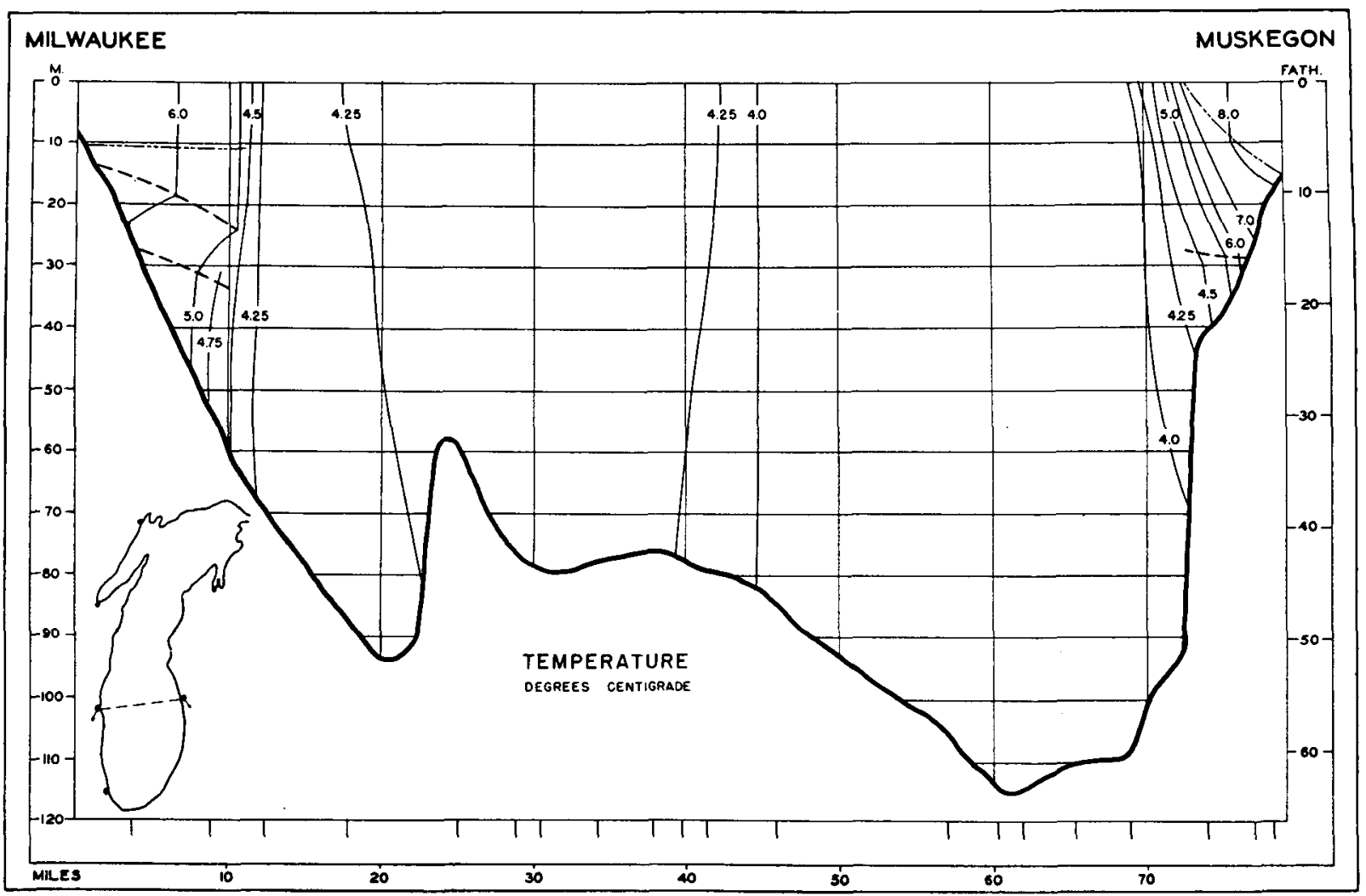

e. May

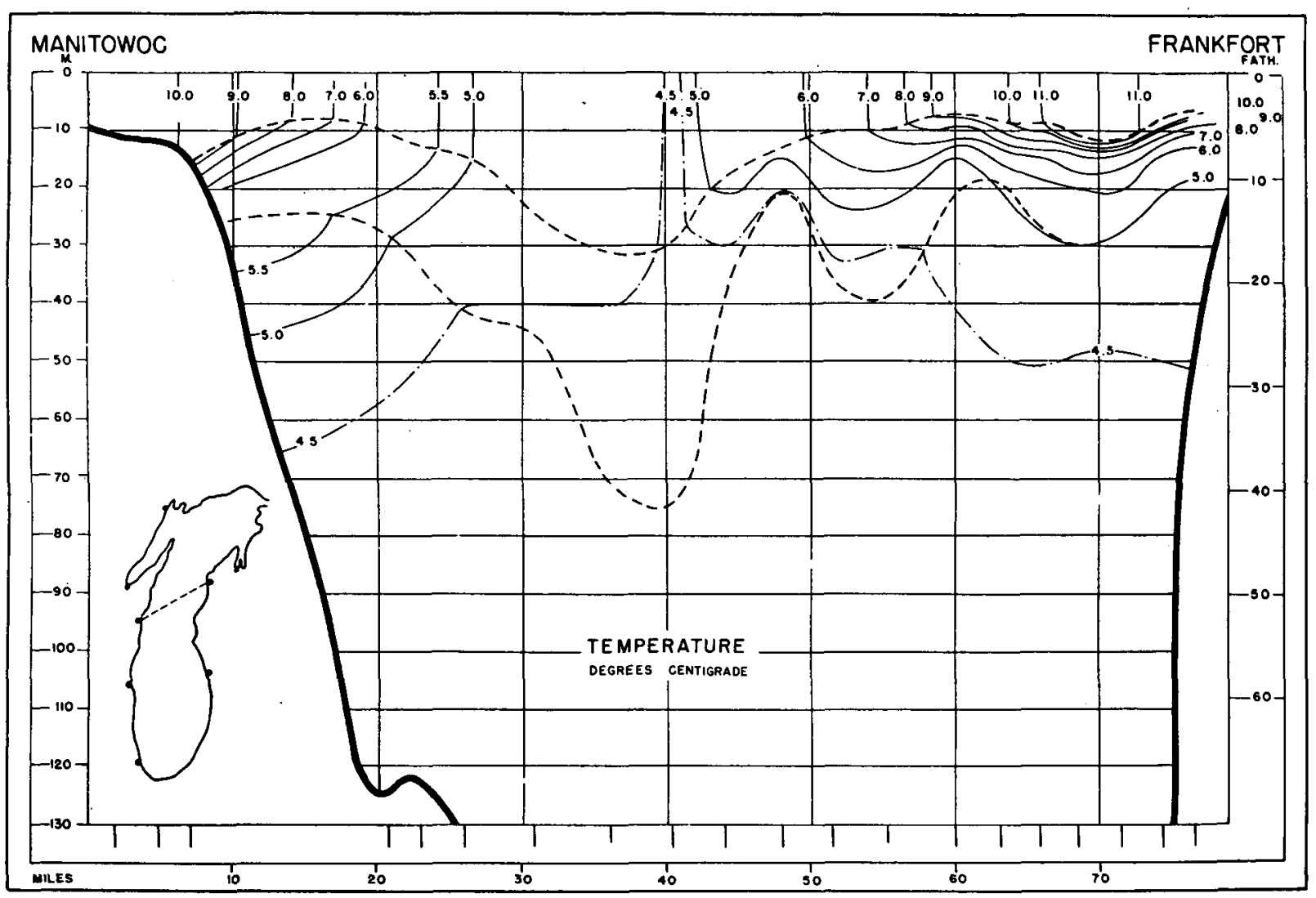

f. June

FIG. 7. (continued) 

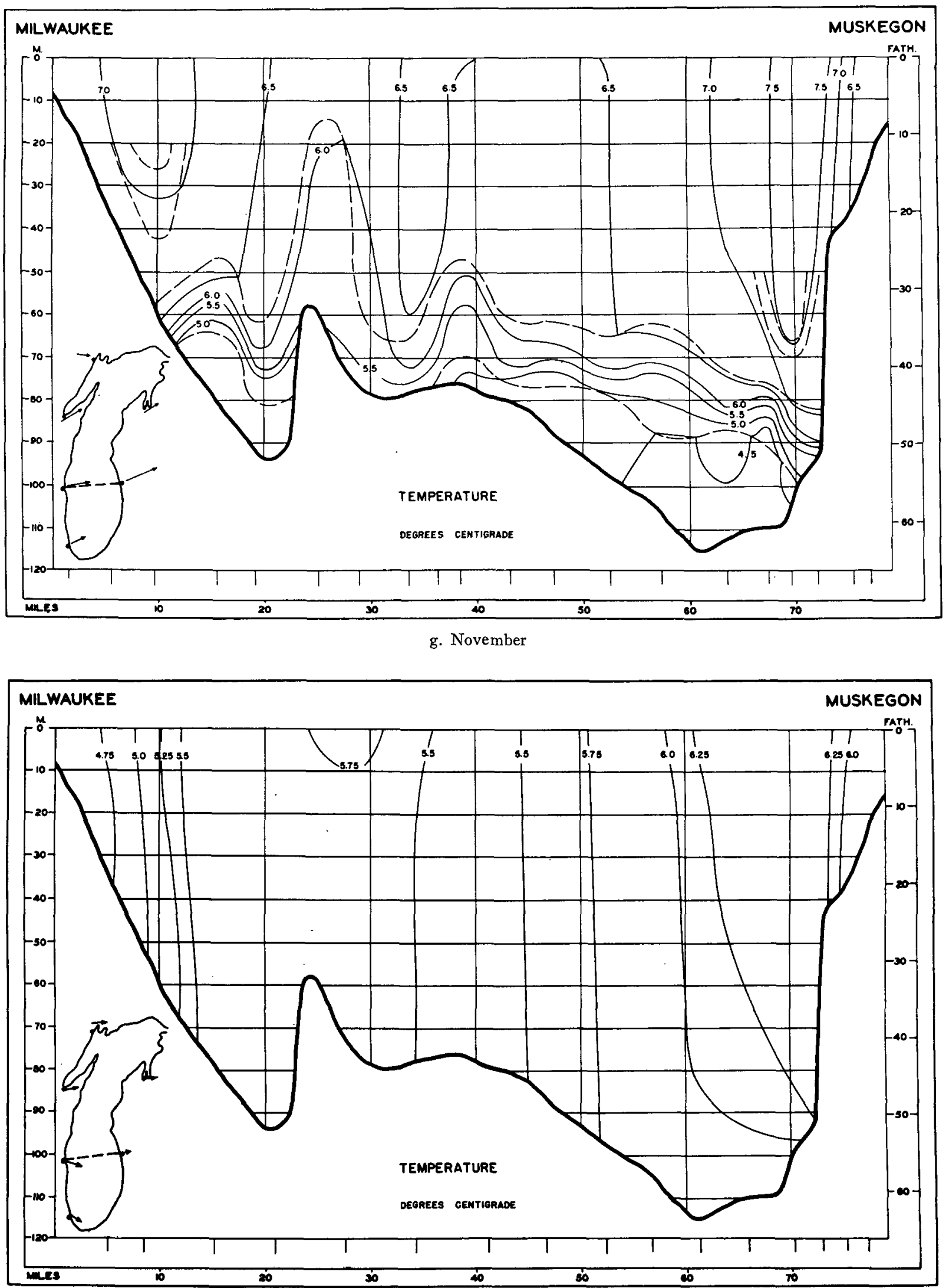

h. December

Fig. 7. (continued) 


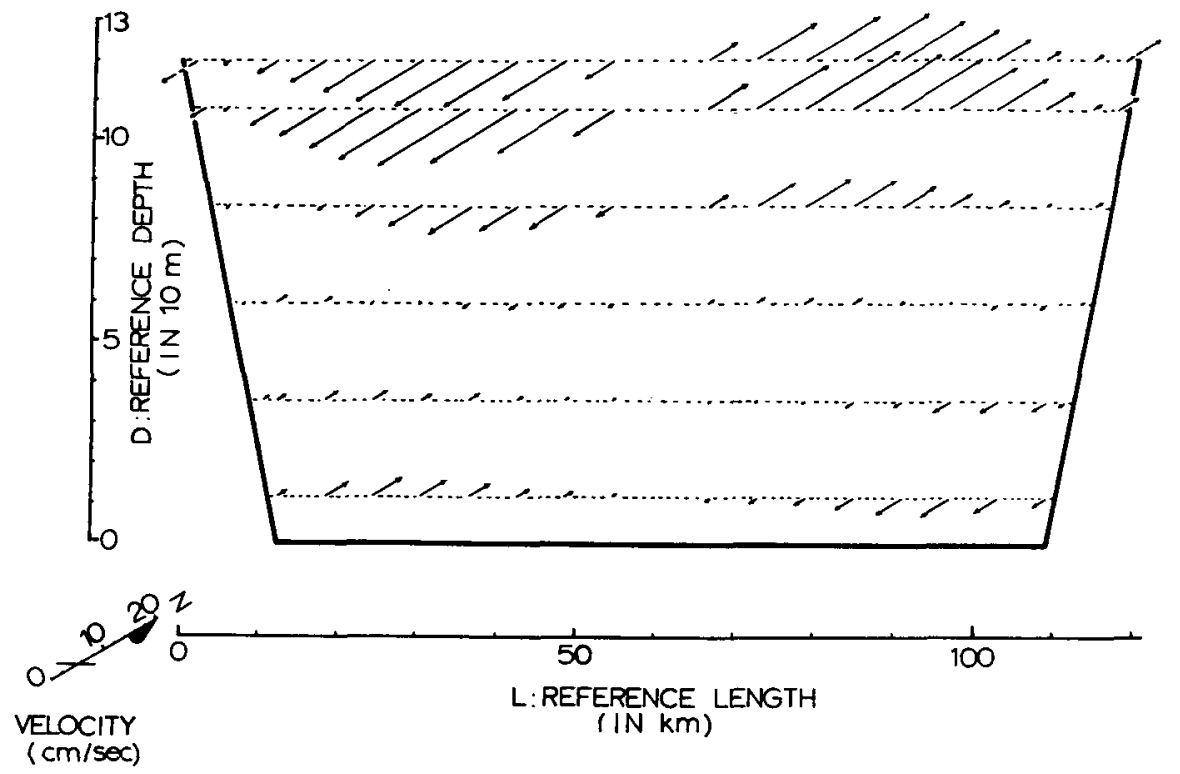

Fig. 8. Nondimensional meridional velocity of the type A circulation in the Lake Michigan model.

The meridional velocity has only a slight change in the upper Ekman layer due to the effect of the boundary layer current. The maximum meridional velocity in the vertical section occurs a few meters below the free surface and its magnitude may reach as high as 20 $\mathrm{cm} \mathrm{sec}{ }^{-1}$ during the summer-heating period. In the lower part of the lake the meridional velocity is much smaller. Below two-thirds of the lake depth, the current direction may reverse with southbound flow in the east and northbound flow near the west.

The zonal velocity $u$ and the vertical velocity $w$ are deduced from (21) according to the definition of the streamfunction $\psi$, which is $O(\epsilon)$ throughout the flow field. Therefore, $u$ and $w$ are $\mathrm{O}(\epsilon)$ in the interior region and may reach $O\left(\epsilon^{\frac{1}{2}}\right)$ in respective boundary regions. With data from Tables 2 and $3, u$ and $w$ have been plotted together in the cross section of the lake as shown in Fig. 9. There are two relatively intensive cells which meet at the middle of the lake resulting in a broad sinking motion in the central portion and upwelling at both the east and west sides. The velocity components in the interior region are mostly vertical with only an $\mathrm{O}\left(\mathrm{R}_{\epsilon}\right)$ part zonally. In the upper and lower Ekman layers, zonal çomponents are dominant but

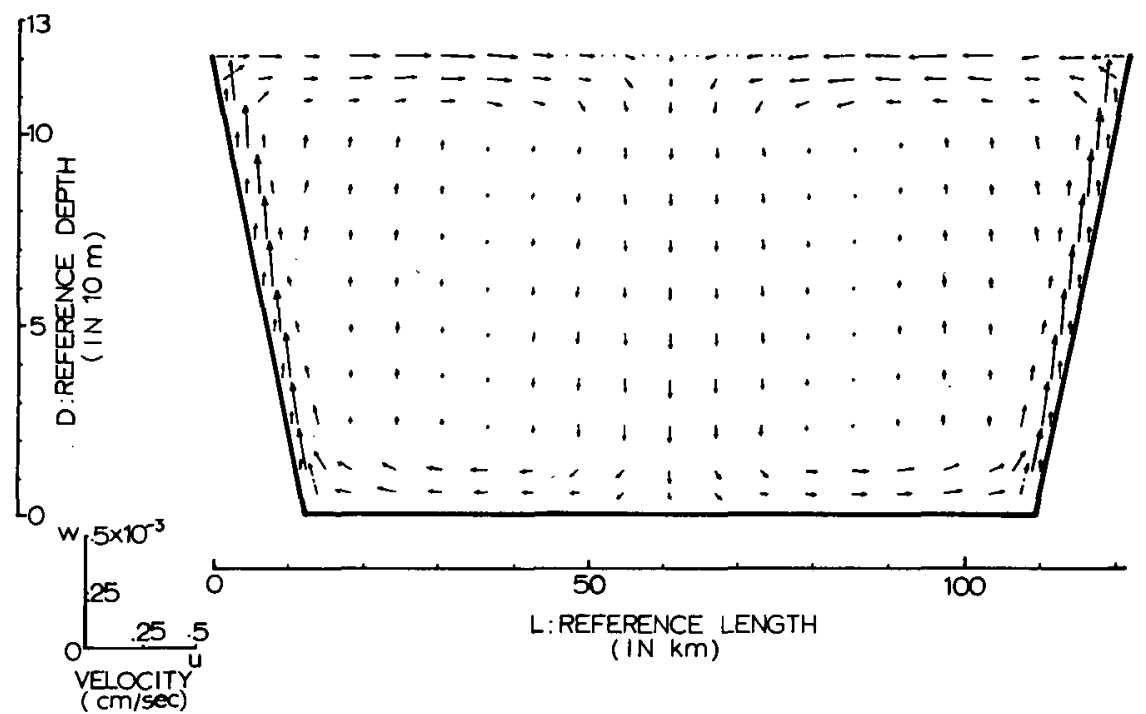

FIG. 9. Nondimensional zonal and vertical velocity components of the type A circulation in the Lake Michigan model. 


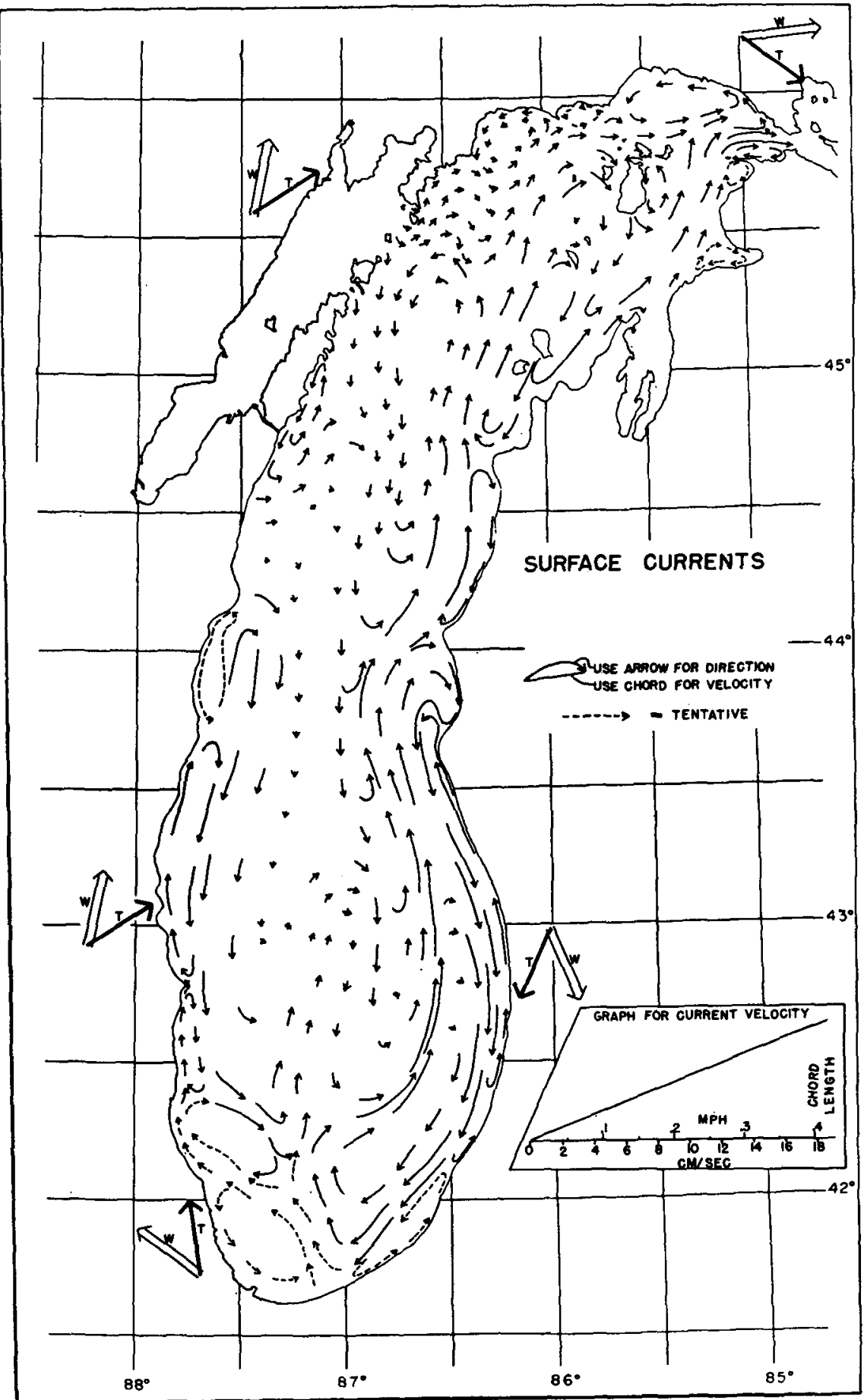

Fig. 10. Observed June surface currents in Lake Michigan (after Ayers et al., 1958).

they are entirely within the surface and bottom boundary regions. On the slant side boundaries, the zonal and vertical velocity are much stronger than in any other place of the flow field. Generally, the magnitude of the mean zonal velocity is less than $1 \mathrm{~cm} \mathrm{sec}^{-1}$ with a maximum near this value at the slant side boundaries. The mean vertical velocity is, in general, in the range of $10^{-5}-10^{-3} \mathrm{~cm} \mathrm{sec}-1$ and may reach a maximum mean value of $2 \times 10^{-3} \mathrm{~cm} \mathrm{sec}^{-1}$ near the side boundaries.

The current during the winter-cooling period possesses the same circulation pattern as shown in Figs. 8 and 9 


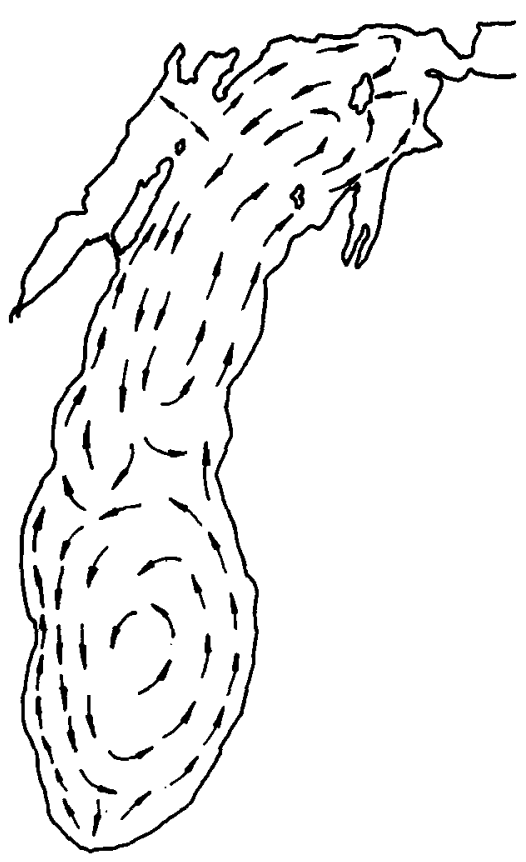

a.

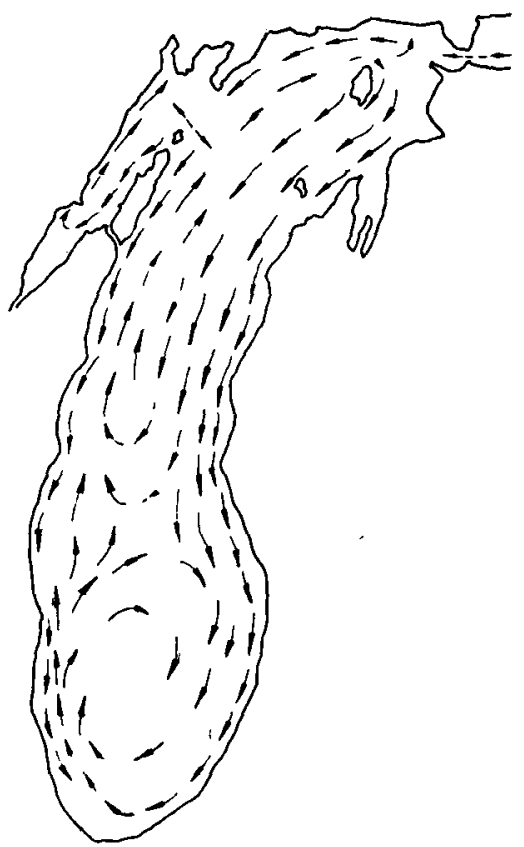

b.

FIG. 11. Two observed basic winter surface current patterns in Lake Michigan (after U. S. Department of the Interior, 1967). See text for description.

except that the magnitude is smaller. The type B circulation is exactly the reverse of the type A circulation pattern.

In our modeling considerations, since Lake Michigan is connected to Lake Huron, the length of the model is considered much longer than the width and the flow is treated as meridionally independent. Actually, the south end of the lake is closed and the Strait of Mackinac also imposes some restrictions on the flow at the north end of the lake. However, we notice that the dominant meridional current is anti-symmetrical to the center line of the lake. Once the ends are closed or restricted, the theoretical flows on each side of the lake can be smoothly connected together at the ends by continuity requirements, while the meridional currents become cyclonic or anticyclonic flows in the lake.

We also notice in Fig. 2 the existence of an everywhere positive north-south meridional temperature gradient. From the results obtained above, we deduce that the cyclonic flow, i.e., the type A circulation, in the lake is strengthened by this meridional temperature gradient, and the anticyclonic flow, i.e., the type B circulation, is weakened.

The configuration of surface current during the navigation season found by Harrington (1895) was reproduced as shown in Fig. 1. His general mean current pattern in Lake Michigan shows a cyclonic circulation. The northward current on the east side of the lake is very well-defined. The southward current on the west side of the lake is weaker. The current in Lake Michigan varies in speed from $10-20 \mathrm{~cm} \mathrm{sec}$. However, Harrington's current pattern has no specific time correspondence with our defined time periods. It agrees well with the summer-heating period, but does not agree with the autumn-cooling period, though our model is not expected to be valid during most of the time of the autumn strong stratification period.

The June surface currents of Ayers et al. (1958) have been reproduced in Fig. 10. Though a relatively weak thermocline had already been formed during the time of their cruises, our summer-heating period circulation pattern should still be observed if there is no drastic change in the lake dynamic system. Ayers' June currents show, in general, a cyclonic circulation with magnitudes $\lesssim 10 \mathrm{~cm} \mathrm{sec}^{-1}$. Qualitatively, the general circulation pattern and speed agree well with our surface currents. Note that the detailed eddy circulations have been neglected in our model study.

From 1962-64 the Federal Water Pollution Control Administration deployed hundreds of temperature and current recording instruments for more than 30 stations all over Lake Michigan. Their preliminary report (U. S. Department of the Interior, 1967) indicates that, generally speaking, surface currents in Lake Michigan are weak and southbound near the west shore, more intense and northbound near the east shore. No permanent type of circulation pattern has been found in Lake Michigan, but four basic patterns have been observed, two in winter and two in summer. Since the reported summer patterns are for the strong stratification period of the lake, they are not included here. The winter surface circulation patterns are reproduced as shown in Figs. 11a and 11b. Fig. 11a is the winter pattern which normally occurs from January to April, 
though not necessarily in a continuous manner. This current pattern shows a general cyclonic circulation which agrees well with the type A circulation during the winter-cooling period. The other winter pattern which is usually found after November through March intermittently is shown in Fig. 11b. This time period is relevant for comparison with our autumn-cooling period which occurs after the thermocline is very deep and weak, or after it disappears. They both show an anticyclonic circulation.

We ran several sets of drogues for the current study in the west side of the lake during the summer of 1968. Currents were generally flowing southward in agreement with our meridional current prediction during the summer-heating period. On the east side of the lake, a tripod-supported pendulum current meter was installed $230 \mathrm{~m}$ offshore at depth of $5 \mathrm{~m}$, from 11 May to 11 October 1967 . The late spring and early summer current directions are summarized in Table 4 . We notice that most of the currents flow northward near the east shore of the lake during the summer-heating period, which agrees well with our meridional velocity solution.

Due to the small magnitudes of the zonal and vertical velocities there is not much field data available for comparison with our theoretical current circulation in the cross section of Lake Michigan. More field observations and precise current measurements are necessary for further studies.

\section{Conclusions}

We have investigated theoretically the thermally induced currents in Lake Michigan. Using the procedure of double perturbation expansions, approximate solutions have been obtained for the whole flow field, except for four unimportant corners. Approximation errors of the solutions are estimated to be the order of (Rossby number) ${ }^{2}$.

The nondimensional temperature distribution has been found as shown in Fig. 6 with isotherms being concave toward the shore on each side of the lake. Two types of circulation patterns have been found for the general thermal current in the lake. The type A current pattern, as shown in Figs. 8 and 9, has a cyclonic twocell circulation with magnitudes reaching $20 \mathrm{~cm} \mathrm{sec}^{-1}$. The type B current pattern is the opposite of the type A pattern, except that the magnitude may be smaller.

In trying to verify the theoretical thermal circulation currents, some field measurements for currents and eddy viscosities were conducted in 1967 and 1968 in Lake Michigan. Comparisons have been made between predictions obtained from our mathematical model study and the previously published field data such as those of Harrington (1895), Church (1942a,b), and of Ayers et al. (1958). Qualitatively, the model lake temperature distribution and the current structure agree very well with the actual field observations in Lake Michigan during the corresponding seasons. This leads
TABLE 4. Percentage of hours current flowed northward, westward, and southward on the east side of Lake Michigan near Benton Harbor, Mich.

\begin{tabular}{lccc}
\hline \hline Month & $\begin{array}{c}\text { Current } \\
\text { northward }\end{array}$ & $\begin{array}{c}\text { Current } \\
\text { westward }\end{array}$ & $\begin{array}{c}\text { Current } \\
\text { southward }\end{array}$ \\
\hline May & 96.7 & 3.0 & 0.3 \\
June & 95.2 & 4.8 & 0 \\
July & 97.1 & 2.9 & 0 \\
\hline
\end{tabular}

one to postulate that the thermal body force does play an important role in controlling the mean lake circulation patterns.

Our theoretical solutions do not show large eddies in the southern and northern basins which have been observed. This is perhaps because the model assumes a flat bottom.

The agreement between the theoretical solutions and the field observations is rather poor in the shallow regions. This may well be the result of the faster response of the shallow water current to wind stresses and of the irregularities of the coastlines. Due to the neglect of wind stresses, the model current circulation is not expected to coincide with instantaneous current measurements, especially in shallow water or in the uppermost surface layer, but it is expected to be valid for the prediction of the mean current circulation pattern in the lake.

Acknowledgments. Material in this paper is part of the author's dissertation at the University of Michigan. $\mathrm{He}$ is greatly indebted to Profs. S. J. Jacobs and J. C. Ayers for their guidance and encouragement throughout the study. The benefit of discussions with Profs. C. S. Yih, A. Wiin-Nielsen and Dr. V. E. Nobel is also acknowledged. The research was supported by National Science Foundation Grant GA-524 and the present paper has been written under sponsorship of the Office of Naval Research, Contract ONR N000 14-69-A-0200-6006.

\section{REFERENCES}

Ayers, J. C., D. C. Chandler, G. H. Lauff and C. F. Powers, 1958: Currents and water masses of Lake Michigan. University of Michigan, Great Lakes Res. Div. Publ. No. 3, 169 pp.

Barcilon, V., 1964: Role of the Ekman layers in the stability of the symmetric regime obtained in a rotating annulus. $J$. Aimos. Sci., 21, 291-299.

Brindley, J., 1960: Stability of flow in a rotating viscous incompressible fluid subjected to differential heating. Phil. Trans. Roy. Soc. London, A253, 1-25.

Carrier, G. T., 1953: Boundary layer problems in applied mechanics. Advances in Applied Mechanics, Vol. 3, New York, Academic Press, 1-19.

Church, P. E., 1942a: The annual temperature cycle of Lake Michigan. University of Chicago, Institute of Meteorology, Misc. Rept. 4, 48 pp.

—-, 1942b; The annual temperature cycle of Lake Michigan. University of Chicago, Institute of Meteorology, Misc. Rept. 18, $100 \mathrm{pp}$.

Csanady, G. T. 1964; Turbulence and diffusion in the Great Lakes. University of Michigan, Great Lakes Res. Div., Publ. 11, 326-339. 
Davies, T. V., 1956: The forced flow due to heating of a rotating fluid. Phil. Trans. Roy. Soc. London, A249, 27-64.

- 1959 : On the forced motion due to heating of a deep rotating liquid in an annulus. J. Fluid Mech., 5, 593-621.

Eady, E. T., 1949: Long waves and cyclone waves. Tellus, 1, $33-52$.

Fowlis, W. W., 1963: An experimental study of the transitions between the flow regimes of thermal convection in rotating annulus of liquid. Ph.D. thesis, University of Durham, England, 188 pp.

- , and R. Hide, 1965: Thermal convection in a rotating annulus of liquid: Effect of viscosity on the transition between axisymmetric and non-symmetric flow regimes. $J$. Atmos. Sci., 22, 541-558.

Fultz, D., 1953: A survey of certain thermally and mechanically driven fluid systems of meteorological interest. Fluid models in geophysics. Proc. First Symposium on the Use of Models in Geophysical Fluid Dynamics, Baltimore, Md., Govt. Printing Office, 27-63.

Greenspan, H. P., 1968: The Theory of Rotating Fluids. Cambridge University Press, $327 \mathrm{pp}$.

- , and L. N. Howard, 1963: On the time-dependent motion of a rotating fluid. $J$. Fluid Mech., 17, 385-404.

Harrington, M. W., 1895: Surface currents of the Great Lakes. U. S. Dept. of Agriculture, Weather Bureau, Bull. B.

Hide, R. 1953. Some experiments on thermal convection in a rotating liquid. Quart. J. Roy. Meteor. Soc., 79, 161.

-. 1958: An experimental study of thermal convection in a rotating liquid. Phil. Trans. Roy. Soc. London, A250, 441-478.

- 1964: The viscous boundary layer at the free surface of a rotating baroclinic fluid. Tellus, 16, 523-529.

Huang, Joseph C. K., 1968: Determination of eddy viscosity and eddy diffusivity in Lake Michigan. University of Michigan, Great Lakes Res. Div. Spec. Rept. 37, part 3, 26-45.

Hunter, C., 1967: The axisymmetric flow in a rotating annulus due to a horizontally applied temperature gradient. $J$. Fluid Mech., 27, 753-778.

Hutchinson, G. E., 1957: A Treatise on Limnology, Vol. I, Geography, Physics, and Chemistry. New York, Wiley, 1015 pp.

Kuo, H. L., 1957 : Further studies of thermal motions in a rotating fluid. $J$. Meteor., 14, 553-558.

McFadden, J. D., and R. A. Ragotzkie, 1963: Aerial mapping of surface temperature pattern of Lake Michigan. Proc. 6th Conf. Great Lakes Research, University of Michigan, Great Lakes Res. Div. Publ. 10, 55-58.

Millar, F. G., 1952: Surface temperatures of the Great Lakes. J. Can. Fish Res. Bd., 9, 329-376.

Okubo, A., and S. Farlow, 1967: Analysis of some Great Lakes drogue studies. Proc. 10th Conf. Great Lakes Research, Intern. Assoc. Great Lakes Research, Ann Arbor, Mich., 299-308.

Robinson, A. R., 1959: The symmetric state of a rotating fluid differentially heated in the horizontal. J. Fluid Mech., 6, 599-620.

U. S. Department of Commerce, Weather Bureau, 1959: Climatology and weather services of the St. Lawrence Seaway and Great Lakes. Marine Area Section, Office of Climatology, Tech. Paper 35, 75 pp.

U. S. Department of the Interior, Federal Water Pollution Control Administration, 1967: Lake currents: A technical report containing background data for a water pollution control program. Water Quality Investigations, Lake Michigan Basin, 364 pp.

Van Dyke, M. 1964. Perturbation Methods in Fhid Mechanics. New York, Academic Press, 229 pp. 